\title{
Maternal alcohol intake induces dramatic ultrastructural changes in offspring brain cortex neurons
}

\author{
Sergey M. Zimatkin* and Lizaveta I. Bon \\ Grodno State Medical University, Grodno, Belarus
}

\begin{abstract}
The aim of the paper was to estimate consequences of alcohol consumption by rats during pregnancy on the brain frontal cortex $5^{\text {th }}$ layer neurons ultrastructure in their offspring. Female Wistar rats consumed a $15 \%$ solution of ethanol as a single source of drinking $(4.64 \pm 2.19 \mathrm{~g} / \mathrm{kg} / \mathrm{day})$ throughout pregnancy, control rats received aquivolume amount of water. The offspring were decapitated on the $45^{\text {th }}$ day after birth and samples of frontal brain cortex were prepared for electron microscopy and histochemistry to examine the $5^{\text {th }}$ layer neurons.

Results: Antenatal alcohol exposure in rats at the $45^{\text {th }}$ day after birth showed a significant reduction in the number of mitochondria per um ${ }^{2}$ of cytoplasm and the total length of their cristae, reduction of the rough endoplasmic reticulum (RER) canal length and their clearance expansion, decrease in the bind ribosomes and increase in the free ribosomes number, expansion of the Golgi apparatus cisternae, increase in the lysosome number and size in the $5^{\text {th }}$ layer frontal cortex pyramidal neurons. The histochemical examination revealed the inhibition of marker enzyme of mitochondria, NADH- dehydrogenase and succinate dehydrogenases as well as activation of marker enzyme of lysosomes, acid phosphatase in the cytoplasm of those neurons.
\end{abstract}

Conclusion: Alcohol consumption by rats during pregnancy induces deep and long-term electron microscopic and histochemical changes in the brain cortex neurons in their offspring.

\section{Introduction}

Alcohol consumption during pregnancy induces the development of a number of specific disorders in offspring that are combined under the term Fetal Alcohol Syndrome (FAS), which is a part of Fetal Alcohol Spectrum Disorders (FASD) [1,2]. According to the published data, the cerebral cortex is particularly sensitive to prenatal exposure to alcohol. Ethanol induces apoptosis, degeneration, reduction in the amount and size of brain cortex neurons, the decrease in their protein content, hypoplasia of cytoplasm [3-7]. There is data suggesting that prenatal alcohol expose reduces the survival of neurons and disrupts their functions causing oxidative stress, DNA damage and mitochondrial dysfunction, as well as suppression of signals of insulin needed to ensure their viability, metabolism, formation of synapses and synthesis of acetylcholine [8-10]. During embryogenesis alcohol induces defects in many molecular, neurochemical and cellular processes that occur during normal brain development, including disturbances of glial functions, regulation of gene expression and cell-cell interactions, increases the formation of free radicals [11]. Ethanol affects the embryonic development of the nervous system, especially the neural stem cells, destroys regulatory communications microRNA that are important for the process of maturation of neurons [12,13]. In the brain cortex of prenatall alcohol expose macaques a 60 -fold increase in apoptosis was observed as compared to the controls. It can explaine the neuropathological changes and long-term neuropsychiatric disorders in those animals [14]. Prenatal alcohol exposure decreases the content of neurotrophic factors in the brain tissues of the embryo. Such changes may underlie some of CNS abnormalities related to the FAS [15].

In our previous paper we described the dynamics of histological changes in the frontal cortex of brain in rats, subjected to antenatal exposure to alcohol. It was found a decrease in neurons body size and number in frontal cortex $5^{\text {th }}$ layer and increase in the number of hyperchromic shrunken neurons there [16].

The aim of the present study is to estimate the effect of prenatal alcohol exposure on ultrastructural and histochemical characteristics of the $5^{\text {th }}$ layer frontal cortex neurons in rats at $45^{\text {th }}$ day after birth.

\section{Materials and methods}

\section{Animals, chemicals and experimental design}

25 female and 10 male Wistar rats were obtained from the breeding colony of the Grodno State Medical University. Their weight was $212 \pm$ 29 g. All experimental procedures complied with European Community Council Directive (86/609/EEC) for care and use of laboratory animals. Protocols were reviewed and approved by the Ethical Committee of the Grodno State Medical University (protocol No1, 11.03.2014). All efforts were made to minimize animal suffering. Rats were housed in vivarium with free access to standard laboratory food and kept under controlled environmental conditions. Rats of the experimental groups throughout pregnancy (from the day of detection of sperms in vaginal smears till delivery) received a $15 \%$ solution of ethanol as a single source of drinking, and the animals of the control group - equivolume amount of water. The average intake of alcohol was $3.64 \pm 2.2 \mathrm{~g} / \mathrm{kg} /$ day.

Correspondence to: Sergey M. Zimatkin, Department of Histology, Cytology and Embryology, Grodno State Medical University, Gorkogo Street, Grodno, 230015, Belarus, Tel: 3750297814742; Fax: (375) (152)335341; E-mail: smzimatkin@mail.ru

Key words: Ethanol consumption, pregnancy, offspring, frontal cortex, neurons

Received: March 12, 2017; Accepted: April 21, 2017; Published: April 24, 2017 
The offspring brains of the control and alcohol groups were examined on the $45^{\text {th }}$ days after birth.

All the chemicals were obtained from Sigma-Aldrich (USA).

\section{Electron microscopy}

For electron microscopy the small pieces of frontal brain cortex were taken, fixed in $1 \% \mathrm{OsO}_{4}$, dehydrated and embedded in epoxy resin. An MT-7000 ultramicrotome (RMC, USA) was used for sectioning. They were contrasted with uranyl acetate and lead citrate, examined using a JEM-1011 electron microscope (JEOL, Japan), and photographed with a digital camera Olympus Mega View III (Olympus Soft Imaging Solutions, Germany). The images of the mitochondria, lysosomes, rough endoplasmic reticulum canal, ribosomes and Golgi apparatus were outlined on the computer monitor by mouse cursor. The numbers, sizes, and shapes of these organelles were evaluated.

\section{Histochemistry}

Pieces of brain cortex were obtained, frozen and stored in liquid nitrogen for further analysis. $10 \mu \mathrm{m}$ serial sagittal sections of the frozen frontal cortex were prepared using cryostat (Leica CM 1840, Germany). The activity of the marker enzymes of mitochondria, succinate dehydrogenase (SDH, EC 1.3.99.1) and NADH dehydrogenase (NADHDH, EC, 1.1.1.49), as well as the activity of marker enzyme of lysosomes acid phosphatase (AP, EC 1.4.3.4) were examined [17]. For the enzyme histochemistry the cryostat sections were placed into the corresponding incubation medium, including the buffer, substrate, cofactor, if necessary, and chromogen, for $30 \mathrm{~min}-5$ hours to visualize the location of enzymatic activity, then washed and embedded in the suitable plastic medium.

The enzyme activities or product of histochemical reactions were determined in cytoplasm of neurons on the optic density of chromogen obtained in the course of histochemical reactions. The examination of preparations, their microphotography and morphometry was carried out using microscope Axioskop 2 plus (Zeiss, Germany) equipped with digital camera (Leica DFC 320, Germany) and computer image analysis software Image Warp (Bit Flow, USA).

\section{Statistics}

The mean values obtained for every animal were processed with nonparametric statistics (because of the small number of animals in the groups) using software STATISTICA 6.0 (StatSoft, Inc., USA). In descriptive statistics, the values of median $(\mathrm{Me})$ and interquartile range (IQR) were determined. The differences were considered significant at $\mathrm{p}<0.05$ (Mann-Whitney U-test), because it was not a normal distribution

\section{Results}

\section{Electron microscopy}

In the $5^{\text {th }}$ layer pyramidal neurons of the frontal cortex of the $45^{\text {th }}$ days offspring of rats, have consumed alcohol during pregnancy the number of mitochondria per unit area of cytoplasm was less than in controls. The mitochondria become more spherical and less elongated, and show the decrease in the number and length of cristae (Figure 1). The general area of mitochondria in cytoplasm of neurons was significantly lower as compared to control (Figure $1 \mathrm{~B}$ and Table 1).

The total number of ribosomes per unit area of the cytoplasm of neurons after antenatal alcoholisation similar as in the controls. But the

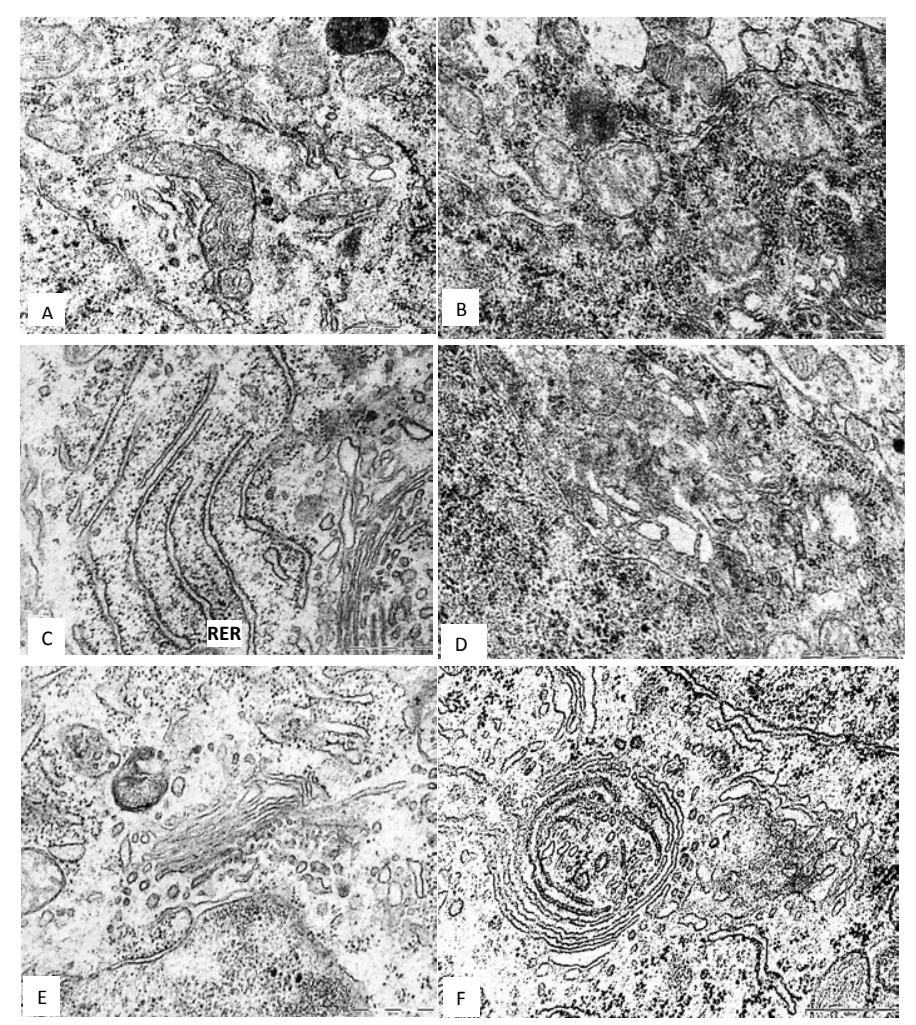

Figure 1. A $5^{\text {th }}$ layer frontal cortex neurons on the $45^{\text {th }}$ postnatal day in controls (A, C, E) and antenatally alcoholised rats $(\mathrm{B}, \mathrm{D}, \mathrm{F})$. M-mitochondria, RER-rough endoplasmic reticulum, G-Golgi complex, L-lysosomes. Magnification: 50,000; scale segment: $0.5 \mu \mathrm{m}$. Electron micrographs.

number of free ribosomes significantly increased and number of bind ribosomes decreased. As a result, the ratio of free and bind ribosomes in cytoplasm of alcoholised rats increased in 10 times (Figure 1D and Table 1). On the $45^{\text {th }}$ day after birth the rough endoplasmic reticulum cisterns length was significantly reduced, but they become wider. The Golgi complex cisterns were greatly enhanced (Figure 1F and Table 1). In some neurons the Golgi cisterns were located concentrically forming unusual cycles (Figure 1F).

Prenatal alcohol exposure increased the amount and size of lysosomes. Their total comparative area in cytoplasm increased in 3 times, as compared to control (Table 1). In addition, in cytoplasm of neurons of alcoholised rats the regions with homogenous osmiofilic hyaloplasm were observed.

\section{Histochemistry}

Histochemical investigation of frontal brain cortex of rats following prenatal alcohol exposure demonstrated the inhibition of the mitochondria marker enzyme NADH-dehydrogenase (from 0.24 to 0.18 units of optical density, consequently), succinate dehydrogenases (from 0.17 to 0.12 units of optical density, consequently) and activation of the marker enzyme of lysosomes acid phosphatase (from 0.23 to 0.35 units of optical density, consequently) in cytoplasm of $5^{\text {th }}$ layer pyramidal neurons (Figures 2 and 3 ).

\section{Discussion}

In our previous paper at the light microscopic level we have demonstrated the dramatic reduction in a number and size of frontal cortex pyramidal neurons of prenatal alcoholised rats at 45 and 90 days 
Table 1. The morphometric analysis of the frontal cortex $5^{\text {th }}$ layer pyramidal neurons organelles.

\begin{tabular}{|c|c|c|c|}
\hline \multicolumn{2}{|l|}{ Index } & \multicolumn{2}{|l|}{$45^{\text {th }}$ day } \\
\hline & & control & alcohol \\
\hline \multirow{7}{*}{ 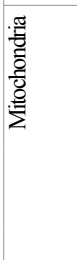 } & Number in $1 \mu \mathrm{m}^{2}$ & $1.9(1.6 ; 2.2)$ & $1.2(1 ; 1.2)^{*}$ \\
\hline & Area. $\mu \mathrm{m}^{2}$ & $0.16(0.15 ; 0.2)$ & $0.19(0.17 ; 0.19)$ \\
\hline & Circularity. unit & $0.62(0.6 ; 0.64)$ & $0.7(0.68 ; 0.8)^{*}$ \\
\hline & Aspect. unit & $2.8(2.76 ; 2.82)$ & $2.6(2.4 ; 2.7)^{*}$ \\
\hline & Number of cristae in $1 \mu \mathrm{m}^{2}$ & $153(125 ; 160)$ & $63(29 ; 79)^{*}$ \\
\hline & Cristae length in $1 \mu \mathrm{m}^{2}$ & $25(25 ; 25)$ & $13(6 ; 16)^{*}$ \\
\hline & Their total area in cytoplasm. $\%$ & $30(24 ; 40)$ & $20(17 ; 23)^{*}$ \\
\hline \multirow{3}{*}{ 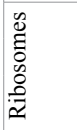 } & Their total number in $1 \mu \mathrm{m}^{2}$ & $16(14 ; 17)$ & $16(14 ; 17)$ \\
\hline & Free. in $1 \mu \mathrm{m}^{2}$ & $7(6 ; 7.4)$ & $15(13 ; 15)^{*}$ \\
\hline & Binding in $1 \mu \mathrm{m}^{2}$ & $9(8 ; 9.2)$ & $1.7(1.2 ; 2)^{*}$ \\
\hline \multirow{2}{*}{$\frac{\widetilde{\alpha}}{\underline{\underline{I}}}$} & Length of cisterns. $\mu \mathrm{m}$ & $2.2(2 ; 2.2)$ & $1.5(1 ; 2)^{*}$ \\
\hline & Width of cisterns. $\mu \mathrm{m}$ & $0.07(0.07 ; 0.074)$ & $0.15(0.1 ; 0.2)^{*}$ \\
\hline 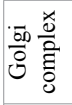 & Width of cisterns. $\mu \mathrm{m}$ & $0.07(0.06 ; 0.08)$ & $0.15(0.12 ; 0.17)^{*}$ \\
\hline \multirow{3}{*}{$\begin{array}{l}n \\
0 \\
0 \\
\vdots \\
0 \\
0 \\
0 \\
\vdots\end{array}$} & Number in $1 \mu \mathrm{m}^{2}$ & $0.5(0.4 ; 0.6)$ & $1(0.8 ; 1.2)^{*}$ \\
\hline & Area. $\mu \mathrm{m}^{2}$ & $0.1(0.1 ; 0.11)$ & $0.16(0.16 ; 0.17)^{*}$ \\
\hline & Their total area in cytoplasm. $\%$ & $5(4 ; 7)$ & $16(13 ; 20)^{*}$ \\
\hline
\end{tabular}

Data is presented as Me (LQ; UQ); * $-\mathrm{p}<0.05$. as compared to controls.

RER - rough endoplasmic reticulum

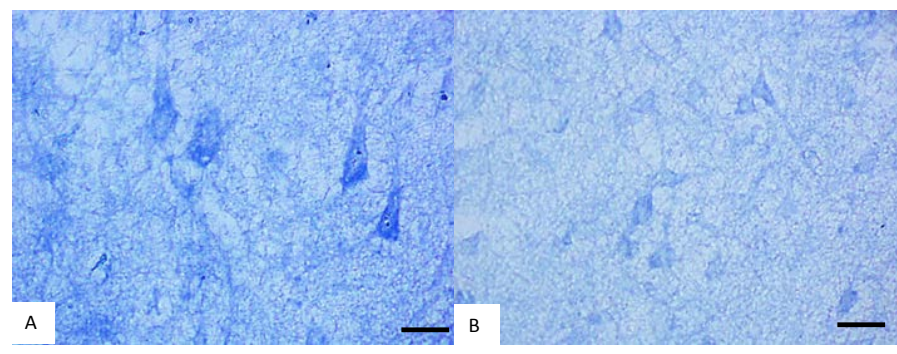

Figure 2. Activity of NADH- dehydrogenase in the $5^{\text {th }}$ layer frontal cortex neurons on the $45^{\text {th }}$ postnatal day in controls (A) and antenatally alcoholized rats (B). Digital microphotography. Scale bars-20 $\mu \mathrm{m}$, magnifications $-40 \mathrm{x}$.
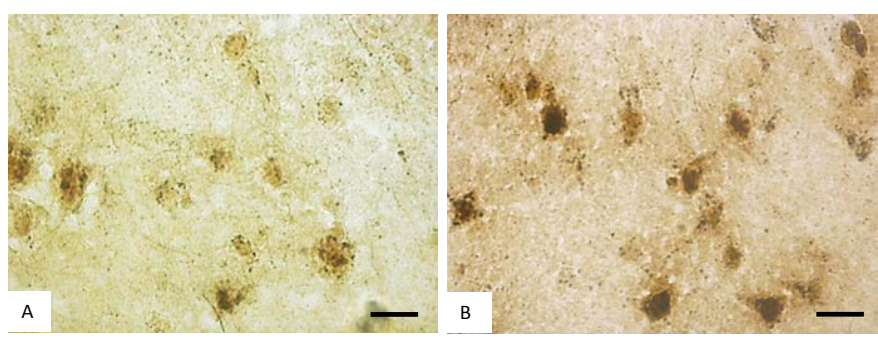

Figure 3. Activity of acid phosphatase in the $5^{\text {th }}$ layer frontal cortex neurons on the $45^{\text {th }}$ postnatal day in controls (A) and antenatally alcoholized rats (B). Digital microphotography. Scale bars- $20 \mu \mathrm{m}$, magnifications $-40 \mathrm{x}$.

after birth. The number of shrunken neurons significantly increased [16].

In the present study, on the ultrastructural level, a brain cortex neurons of prenatally alcoholized rats displayed both destructive and compensatory adaptive changes. The mitochondria were swelling, and showing the decrease in the density of cristae, as well as reduction of their area. It is corresponding to the decrease in activity of their marker enzymes, succinate and NADH-dehydrogenases, in the cytoplasm of those neurons at the light microscopic level. The hyperplasia of free ribosomes and hypertrophy of Golgi complex may reflect an activation of the synthetic processes in those neurons for their own needs for compensation of the damaged or lost structures to survive following the antenatal alcohol action. A reduction of bind ribosome number and RER canals indicate a decreased of protein biosynthesis for export to nerve terminals. That can disturb functions of neurons. The significant increase in the amount and size of lysosomes in neurons studied accompanied by an activation of the lysosomal marker enzyme acid phosphatase (at light microscopic level) may reflect the increased autophagy for the removal of alcohol-damaged microstructures.

Thus, antenatal alcoholization causes profound and diverse ultrastructural changes in the frontal cortex neurons of rat brain, which correspond to the structural and histochemical abnormalities in them at the light microscope level.

Identified morphological and metabolic disturbances in the brain cortex neurons may underlie the known neurological and behavioral disorders in animals and human after antenatal alcohol exposure [18].

In conclusion, alcohol consumption during pregnancy in rats induces deep long-term structural and metabolic disturbances in the frontal cortex neurons in offspring.

\section{Funding}

Grodno State Medical University grant for reagents and animals.

\section{Conflict of interest}

None declared.

\section{References}

1. Jones KL, Smith DW, Ulleland CN, Streissguth P (1973) Pattern of malformation in offspring of chronic alcoholic mothers. Lancet 1: 1267-1271. [Crossref]

2. Lemoine P (2012) The history of alcoholic fetopathies. 1997. J Popul Ther Clin Pharmacol 19: e224-226. [Crossref]

3. Riley EP, Infante MA, Warren KR (2011) Fetal alcohol spectrum disorders: an overview. Neuropsychol Rev 21: 73-80. [Crossref]

4. Alvarez MR, Stone DJ (1988) Hypoploidy and hyperplasia in the developing brain exposed to alcohol in utero. Teratology 37: 233-238. [Crossref]

5. Miller MW (1986) Effects of alcohol on the generation and migration of cerebral cortical neurons. Science 233: 1308-1311. [Crossref]

6. Miller MW (1993) Migration of Cortical Neurons is Altered by Gestational Exposure to Ethanol. Alcohol Clin Exp Res 17: 304-314. [Crossref]

7. Fabregues I, Ferrer I, Gairi JM (1985) Effects of prenatal exposure to ethanol on the maturation of the pyramidal neurons in the cerebral cortex of the guinea pig: a quantitative Golgi Study. Neuropathol Appl Neurobiol 2: 291-298. [Crossref]

8. De la Monte SM, Wands JR (2010) Role of central nervous system insulin resistance in fetal alcohol spectrum disorders. J Popul Ther Clin Pharmacol 17: e390-e404. [Crossref]

9. De la Monte SM (2011) si-RNA inhibition of brain insulin or insulin-like growth factor receptors causes developmental cerebellar abnormalities: relevance to fetal alcohol spectrum disorder. Mol Brain 4: 13-21.

10. Aros S, Mills JL, Iñiguez G, Avila A, Conley MR, et al. (2011) Effects of prenatal ethanol exposure on postnatal growth and the insulin-like growth factor axis. Horm Res Paediatr 75: 166-173. [Crossref]

11. Alfonso-Loeches S, Guerri C (2011) Molecular and behavioral aspects of the actions of alcohol on the adult and developing brain. Crit Rev Clin Lab Sci 48: 19-47. [Crossref]

12. Balaraman S, Winzer-Serhan UH, Miranda RC (2012) Opposing Actions of Ethanol and Nicotine on MicroRNAs are Mediated by Nicotinic Acetylcholine Receptors in Fetal Cerebral Cortical-Derived Neural Progenitor Cells. Alcohol Clin Exp Res 111: 1669-1677. [Crossref]

13. Miranda RC (2012) MicroRNAs and Fetal Brain Development: Implications for Ethanol Teratology during the Second Trimester Period of Neurogenesis. Front Genet 3: 77-82. [Crossref] 
14. Farber NB, Creeley CE, Olney JW (2010) Alcohol-induced neuroapoptosis in the fetal macaque brain. Neurobiol Dis 40: 200-206. [Crossref]

15. Heaton MB, Swanson DJ, Paiva M, Walker DW (1992) Ethanol exposure affects trophic factor activity and responsiveness in chick embryo. Alcohol 9: 161-166. [Crossref]
16. Zimatkin SM, Bon EI (2017) Dinamics of histological changes in the frontal cortex of the brain in rats subjected to antenatal exposure to alcohol. Neurosci Behav Physiol 47: 370-374.

17. Pearse AGE (1960). Histochemistry: theoretical and applied ( $2^{\text {nd }}$ edn). London: Churchill.

18. Mattson SN, Riley EP (1997) Neurobehavioral and Neuroanatomical Effects of Heavy Prenatal Exposure to Alcohol. - Seattle, WA: University of Washington Press.

Copyright: $@ 2017$ Zimatkin SM. This is an open-access article distributed under the terms of the Creative Commons Attribution License, which permits unrestricted use, distribution, and reproduction in any medium, provided the original author and source are credited. 